\title{
Open innovation in the public sector: drivers and barriers for the adoption of Challenge.gov
}

\author{
Ines Mergel (D) \\ Department of Politics and Public Administration, University of Konstanz, Konstanz, Germany
}

\begin{abstract}
Online Open Innovation (OI) platforms like Challenge.gov are used to post public sector problem statements, collect and evaluate ideas submitted by citizens with the goal to increase government innovation. Using quantitative data extracted from contests posted to Challenge.gov and qualitative interviews with thirty-six public managers in fourteen federal departments contribute to the discovery and analysis of intra-, inter, and extra-organizational factors that drive or hinder the implementation of $\mathrm{Ol}$ in the public sector. The analysis shows that system-inherent barriers hinder public sector organizations to adopt this procedural and technological innovation. However, when the mandate of the innovation policy aligns with the mission of the organization, it opens opportunities for change in innovation acquisition and standard operating procedures.
\end{abstract}

KEYWORDS Online Open Innovation platforms; barriers for e-government adoption; government innovation; crowdsourcing innovations

\section{Introduction}

Open innovation (OI) is the process of crowdsourcing solutions to organizational problems to ensure organizational survival or renewal (Chesbrough 2003). Online platforms are used to announce product design contests, such as Lego's design of new sceneries, or Netflix's search for a new algorithm to suggest movies to its users. The knowledge of traditional innovators like R\&D departments in private sector organizations is supplemented by including external amateurs who are not part of the organization into the product design process using monetary incentives to encourage participation (Chesbrough and Crowther 2006).

Similarly, public sector organizations are using OI approaches to access knowledge from citizens. For that purpose and as part of the Digital Government Strategy, the US federal government established a new policy instrument to access knowledge of external problem solvers, such as citizen scientists or citizen hackers (The White House 2009). The policy and follow-up executive mandates (The White House 2010) support the America Competes Act (2007) designed to increase economic development and the effectiveness and efficiency of public service delivery. US federal government agencies are using a shared online platform called Challenge.gov to post their problem statements and collect ideas from citizens. 
However, OI approaches are challenging for public sector organizations: the traditional innovation acquisition process is highly regulated and follows strict rules and regulations, while OI processes are by design open and have few rules. Arundel et al. provide a three-prong model: bottom-up, policy-dependent, or knowledge-scanning innovation methods of public sector agencies in their analysis of over 3,000 European government agencies (2015). Government organizations are either working with a group of pre-approved vendors and contractors who are responding to requests for proposals, which are then internally vetted before a solution proposed by a vendor is implemented. Or, innovations are driven by policy mandates as a source of innovation in the public sector. The Affordable Care Act in the United States for example led to the creation of a new online marketplace, HealthCare.gov, a technological as well as procedural innovation that was not available in government before. Selected government agencies, such as the Defense Advanced Research Projects Agency (DARPA), are designed to create research collaborations with outsiders, including University partners to increase their access to innovations (Colatat 2015). These forms of internal innovation creation following the standards of the bureaucratic governance process is called 'closed innovation' (Felina and Zenger 2014). Stepping outside of the formalized innovation acquisition process with contractual relationships and opening up the innovation process to amateur problem solver is therefore a challenge for public sector organizations.

This article builds upon the existing OI literature in the private sector by adding a new empirical context to enhance our understanding of barriers to innovative e-governance practices. E-governance in this case is analysed to understand a technological innovation - the Challenge.gov platform - and a managerial innovation - a change from traditional contract- and grant-based innovation acquisition to crowdsourcing of innovative problem solutions. The longitudinal study spans the time from 2010 to 2014 to understand how public managers perceive factors that hinder or support the implementation process. The result is a multilevel analytical framework of barriers that work against and drivers that foster the implementation of a technological and managerial innovation.

The key contributions of this article are to add a new empirical case that has not been developed in the literature: OI in the context of government; and a multidimensional analytical approach that not only takes in-house barriers of e-government in a single organization into account, but also reviews drivers and barriers at the intra-, inter-, and extra-organizational levels of analysis focusing on all federal agencies engaged in OI practices.

The current OI literature focusses almost exclusively on private sector organizations. However, as Meijer (2015) states, the literature on public innovation and e-governance needs to go hand-in-hand. Both bodies of literature aim to understand how government organizations can respond to societal challenges, changing demands by citizens, and the need to provide services in a more efficient and effective manner.

The research questions include: What are the empirical factors that hinder the implementation of OI practices in public sector organizations? And, What are the empirical factors that drive the implementation of OI practices in public sector organizations? To answer these questions, the article first provides a review of the current state of the OI literature and then applies the OI concept to the public sector context. The research design outlines the data collection and analysis steps combining data from the online platform Challenge.gov and interviews with public managers. 
The findings are organized along three levels of analysis and provide insights into intra-, inter-, and extra-organizational factors for OI.

\section{Literature review: OI in the public sector}

OI is an umbrella term that describes processes, outcomes, and business models of a new form of innovation creation. OI approaches appeared first in the private sector allowing organizations to explore new clientele, market segments, or the invention of new products and designs. Current OI studies focus predominantly on research and development-intensive industry organizations (Murray et al. 2012; Villarroel 2013). Practices and research have only minimally been expanded to the public sector.

\section{The Ol process}

Chesbrough defined the OI process as a new form of purposive inflows and outflows of knowledge to accelerate internal innovation and expand the markets for the external use of innovation (2003). OI approaches are using crowdsourcing and peer production processes to invite the public to co-create solutions for organizational problems (Benkler 2006). Using Howe's 'wisdom of the crowds' notion to add citizen's knowledge in incremental pieces to the overall solution, crowdsourcing processes need to be supported by an online platform to advertise and collect solutions from a geographically distributed crowd (Howe 2006; Surowiecki 2004). Some contest processes expand the innovation collection phase and include crowd judging or crowd improvement of the selected solutions (Mergel 2015).

\section{Factors influencing the adoption of $\mathrm{Ol}$ processes}

Factors influencing the adoption of OI processes in the private sector include the role of individuals and teams in designing and managing contests ( $\mathrm{Du}$, Leten, and Vanhaverbeke 2014; Ettlie and Elsenbach 2007). While in the private sector, employees sometimes aim to protect their current inventions, public sector employees are not hired to constantly search for new markets, ideas for new products, or even to actively seek out return customers to ensure the survival of the organization.

The openness versus closeness characteristics of the search process oftentimes influences the outcomes or the extent of OI adoption. Salge et al. found that too little and too much openness in the search process is related curvilinear to the outcomes of OI processes and the definition of the goal of the contest is oftentimes problematic for organizations (2013). If problem solvers do not feel that they can contribute a meaningful solution, or the solution is too simple to attract the right problem solvers, the contest might not lead to the expected outcomes (Jeppesen and Lakhani 2010; Lakhani and Jeppesen 2007; Dahlandera and Piezunkab 2014). In public sector organizations, this might not even be a problem of designing a sophisticated and appropriate search process, instead regulatory government organizations in the United States are prohibited by law to actively seek citizen input and are limited to certain types of regulated interactions. This can in turn reduce the adoption and implementation of OI processes in some government agencies.

At the organizational or system level, existing research has focussed on the general cultural climate that supports innovation acquisition. Opening the organizational 
boundaries and subsequently agreeing to support the initial costs to design and (re) organize the organizational procedures to allow an OI approach requires a paradigm shift of top management as well as organizational units involved in the implementation process (Murray et al. 2012). In the public sector, changes in standard operating procedures need to be vetted, tested, and approved by top management and flexibility in adjusting organizational rules rarely exists (DeHart-Davis, Chen, and Little 2013).

Similarly, the existing OI literature looks at these issues from an inter-organizational perspective in which OI occurs, such as policy development and the need for implementation of new governance approaches to OI - deciding whether the system as a whole allows an open or closed innovation approach (Felina and Zenger 2014). These decisions are rarely made bottom-up in the public sector. Instead all processes and interfaces with the public or other organizations are designed to ensure accountability. In government, public managers perceive the existing red tape - a set of rules and regulations governing an organization's behaviour - as hindrances for the adoption of innovations (Rainey, Pandey, and Bozeman 1995). However, acquisition procedure following a request for proposals process and formal contracts with contractors and vendors lead to a maximum of accountability and reduce risk for contract managers.

Extra-organizational factors focus on the role of stakeholders located outside the organization and include the role of users and consumers of OI processes, the changing needs of society, and recent technological developments. For example, are there external problem solvers that are willing to participate in the process or is there an existing OI network and community that might be interested in taking on problem solving for the organization (West and Lakhani 2008; Piezunka and Dahlander 2015). Ropera et al. have shown that opening the organization for knowledge in-flows can in turn have positive externalities and influence a positive climate and image of the organization (2013). As a result, openness incentivizes problem solvers to provide their knowledge and help create a solution (Fu 2012). However, the relationship between the solution seeker and solvers can result in an unbalanced power relationship with different incentives for each participating party (Gambardella and Panico 2014).

Other extra-organizational factors - outside the direct influence sphere of the focal organization - include larger societal factors, such as the trend of using crowdsourcing and crowdfunding approaches as an acceptable interaction mechanism between organizations and stakeholders (Howe 2006; Shirky 2008). This aspect is closely coupled with the development of public participation platforms and increases the general digital literacy that allows stakeholders to participate in the process. In addition, societal aspects can also be considered as new forms of industry or contractor relationships.

Previous research on OI in the public sector found several important benefits for public sector organizations. Mergel and Desouza found that OI approaches are used to increase awareness of changes in policy or aim to recruit eligible parties to gain their attention to programmes (2013). The main goal is to reach otherwise disconnected parts of the population who are never in contact with government but might have valuable insights on how public service delivery should be designed to reach them.

Contests submitted by public managers on Challenge.gov mostly focus on awareness raising for societal problems and the availability of public services and programmes, public service improvement to create citizen satisfaction, in form of speed 
or reliability of public services, as well as knowledge-seeking initiatives or the call for technical solutions (Mergel et al. 2014). Rarely do OI processes lead to radical or disruptive innovations in the public sector. The most innovative outcomes are realized in science and technology-oriented agencies, including NASA which ran a contest to capture meteors or change their trajectory to avoid collision with earth (NASA n.d.).

Other related engagement concepts in the public sector focus on co-production of public services (Joshi and Moore 2004), co-development of public policy in form of e-rulemaking processes (Coglianese 2004), or collaborations with the public in budgeting processes (de Sousa Santos 1998). These procedures invite citizens to create a public good and with their early participation in governance processes increase trust, accountability, and ultimately higher degrees of buy-in for the final budget, policy, or service. However, OI processes by design go beyond localized communities who are directly affected by a policy, instead the recruitment of problem solvers is designed to access knowledge from mostly nonprofessional problem solvers who are usually not part of the participation processes. In addition, OI projects incentivize participation with monetary prizes that can be of smaller denomination but oftentimes reflect the value an organization would pay for a contractor or vendor to provide the solution through a contract or grant.

As Lee et al. state, national-level policies for the implementation of OI approaches have just recently been designed in the public sector and government organizations are in the very early stages of the implementation process (2012). In an environment without prior experience of opening up the formal innovation creation process, with multidimensional innovative practices that include technological innovations, process innovations, and outcome innovations, it is therefore important to understand how government organizations perceive the challenges of a new governance instrument.

Equally important for the development of a theory of OI is an understanding of the factors that foster the implementation. The research framework presented in this article explores these factors at three different levels of analysis: (a) extra-organizational and societal factors; (b) inter-organizational or system-wide factors that influence government organizations as a whole and in their interactions with each other; and (c) intra-organizational factors that are individual to each agency, its specific political context, mission, and organizational culture.

\section{Research design: data collection and analysis}

The sample for studying OI in the public sector includes all US federal government agencies using the crowdsourcing platform Challenge.gov from 2010 to 2014, the first 5 years of its existence. Agencies in this sample are comparable because they all received the same Presidential mandate, operate in comparable political environments, and simultaneously have to find ways to implement the mandate. This fullcensus approach not only allows the inclusion of the whole population of adopters but also focusses the data analysis efforts on similar cases that are facing the same technological, cultural, and organizational circumstances when they are adopting and implementing a new policy. The range of participating agencies is wide enough to understand systematic differences between agencies with a variety of missions and 
diverse sets of stakeholders. The sample might have limitations, because it does not include non-adopters.

The data collection was designed in two phases: in the first phase, contests posted by federal agencies and departments during the first 5 years of existence of Challenge.gov were extracted from the platform. A research team reviewed problem statements, target problem solvers, monetary and non-monetary incentives, duration of the contests, possible indications of different contest phases, and expected outcomes. In iterative discussions with two research assistants, each contest was analysed, compared, and categorized according to the researchers' judgments. Challenges were coded based on similarities of problem statements and categorized into awareness, service, knowledge, and technical solutions. The contests were sorted by agency and year posted. The result of this exploration is that a total of thirty-six agencies used Challenge.gov to post their public management problems representing fourteen of the fifteen departments of the US federal government. The site itself allowed for limited data collection that represented the data points listed above and did not reveal any information about internal decision-making or strategic thinking behind the use of the site.

To compensate for the limited availability of public data, in a second data collection phase, the agencies that posted contests on Challenge.gov were invited to participate in a qualitative interview study to elicit the perceptions of public managers in charge of designing and managing prizes and contests for their agencies. Thirty-six public managers participated in semi-structured interviews that lasted between 60 and $90 \mathrm{~min}$.

The interview outline was informed by the analysis of the contests and the existing literature on OI. The questions focus on organizational factors influencing the decision to follow the Presidential mandate, the internal strategic and managerial decision-making processes that preceded posting of challenges online, marketing strategies to reach the desired audience of problem solvers, intended and actual outcomes, implementation of the contest outcomes, as well as lessons drawn from the process. Each interview was recorded with the permission of the subjects, transcribed verbatim, and hand-coded line-by-line.

The narrative analysis was designed to develop a case-oriented understanding of the phenomenon itself, but from the viewpoint of public managers who are participants in the social phenomenon. This type of interpretative approach helps to gain a deeper understanding of intra-organizational decision-making processes, strategic conversations behind closed doors, managerial implementation problems, and trial and errors that occur. These data are not publicly observable through an online ethnographic approach and cannot be experimentally examined or measured using quantitative metrics, such as intensity, amount, or frequency measures (Denzin and Lincoln 2011). The goal is not to derive causal relationships; instead the narrative analysis of the interviews with programme managers helps to identify common themes among the agencies included in the study (Miles, Huberman, and Saldana 2014).

\section{Findings}

The findings of how the US federal government agencies adopted the use of Challenge. gov to post OI contests can be divided into two main factors: (a) drivers for the adoption of OI approaches; and (b) barriers for the adoption of OI approaches. Each set of factors is divided into intra-, inter-, and extra-organizational factors. 


\section{Finding 1: drivers for Ol}

Except for NASA and DOD's DARPA, none of the agencies posting challenges to Challenge.gov expressed an initial internal need to solve certain types of problems. As a matter of fact, all agencies said that they have in-house experts and in cases they cannot find a solution, they hire contractors. Needs were created through OSTP staff who went through the secretaries of departments or administrators of agencies to convince top leadership to test the new policy instrument. The national priorities of the White House's Open Government initiative have driven initial tests, such as mobile application challenges to encourage the use of datasets posted to Data.gov:

We worked with the Executive Office of the President, which got us involved in the challenges, and then Safety.data.gov. We are trying to build those bridges within our organization and outside of our organization, to ideally help the field. It came about in a very straightforward manner. We are meeting regularly with the CTO's office of the President. The then Technology Officer, Anish Chopra, told us that he wanted us to do a challenge and he wanted it out in two weeks.

Findings show that the main driver for the adoption of OI approaches is top-down mandates, which then lead to early experimentations with contests and prizes. Rarely do agencies go beyond the formal mandate to adopt OI, except for science and technology agencies like NASA, which had gained experiences inviting professional coders to solve technology problems using the OI platform TopCoder. All other agencies jumped on the bandwagon as a result of several follow-up executive orders and memos, such as the Innovator's Toolkit (The White House 2010). However, before any of them was able to post and promote their contests on Challenge.gov, they had to overcome institutional, legal, managerial, and cultural barriers. This process can take up to 2 years, before an agency is finally able to post an OI contest.

\section{Intra-organizational factors}

The intra-organizational drivers emerge at two different stages of the process: (1) before the policy was officially published, and (2) after the policy instrument was available to agencies. Pre-implementation, few agencies used OI approaches proactively to initiate external searches for problem solvers outside the traditional grants and contracts instruments. Only one agency was already interested in exploring opportunities to invite problem solvers into the organization:

We wanted to use innovations, or use the tools and resources available to us to do things that are innovative to solve some of the [problems], meet some of our strategic goals, that we may not be able to get at conveniently or expeditiously through more traditional mechanisms.

As a matter of fact, most government employees experienced the need to access external knowledge free from the constraining context of the existing rules and regulations.

\section{Top-down management decision}

In most of the agencies, the pressure to adopt OI approaches was pushed down from the top of the agency to the implementers. Even the simple request to populate the 
Challenge.gov platform came from top management, as one public manager points out

I'm not sure if it came from our immediate supervisor, or the supervisor's supervisor: but it came down that Challenge.gov is launching; we need to have challenges to be there when it launches, because we were one of the first challenges on Challenge.gov. So it was told us that we needed to do a challenge, and to think of a challenge.

This shows that adoption was not an emergent bottom-up, experimental process, instead public managers were told to align their procedures with the policy requests.

The extent to which agencies then started to internally experiment with a crowdsourcing process is driven by the mission - the core task of an agency. As an example, a public management problem occurs that influences all subagencies and teams within a large department and still cannot be solved internally. As a result, an idea emerges, needs top-down approval to be posted on Challenge.gov, and then manifests itself in an actual contest. One public manager describes the process in a public health agency:

Actually the assistant secretary was the one who initiated both of them. She is the sole approval authority within [our agency], so she is the only one who can sign off on anybody doing a prize challenge in [our agency]. The most recent Twitter challenge, the now trending challenge hashtag 'Health in My Community', was proposed by our operational data analytics team that's called 'The Fusion Cell.' They had spoken with state, local regional, tribal and territorial representatives over the course of several months, investigating ways to utilize the different data sources that were available via various social networking mechanisms.

Another public manager added: 'I mean the impetus came from the White House to our administrator to us. Our administrator was very supportive of us using [Challenge.gov].'

\section{Strategic alignment with the organizational mission}

For most agencies, the support of the organizational mission and alignment with their own innovation strategy are key drivers to use an OI approach instrument. Mission alignment ranges from reputational gains, for example being seen as an innovator, to creating awareness and educating the public about available public programmes. One manager explains: '[Our agency] benefits just in general from running competitions and getting our name out there and [being] associated with things that are innovative and working with startups and early stage companies.' Agencies did not have opportunities to fulfil this part of their strategic innovation plans using the existing instruments. The Prizes and Contests policy allowed them to reach out in innovative ways.

\section{Connect to new communities of problem solvers}

The traditional innovation acquisition instruments limit government's access to problem solver communities that are not already pre-approved on acquisition schedules or solutions to problems cannot simply be solved by an existing long-term contract. Agencies stated that they were in a holding pattern: knowing that they had to reach out to emergent communities of problem solvers to get access to potentially non-standard ideas, they did not have an instrument that allowed them to interact with these problem solvers. One public manager stated the need to improve the current innovation practices: 
I think there is just an overall embrace in general about looking at new ways of doing work and having outside people help us with the work that we do.

OI approaches provide government with innovative ways to reach out to the academic community and especially student problem solvers who might have already been working on similar projects. The other larger stakeholder group includes software developers who were encouraged to collaborate with government to create mobile applications using open data.

\section{Inter-organizational drivers}

The General Service Administration (GSA), the agency in charge of providing the Challenge.gov platform, recognized early that the Presidential mandate was not immediately implemented. GSA initiated roadshows, phone conferences, and webinars to provide trainings and best practices that helped to initiate intra-organizational conversations about prizes and challenges. In collaboration with OSTP, federal agencies were trained to adopt contests, as one programme manager explained:

OSTP set up a center of excellence at [agency] for challenges and prizes and we worked with [name] in particular for the Big Data ideation challenge. It is a government-wide opportunity that I see OSTP has taken the lead in making that all of the agencies understand that it's legal to do competition and prizes, where probably before we would have felt we didn't have the right or the authority to do such a thing. They clarified the rulings, the legalities of all of that, and then they gathered best practices. This was trying to educate the folks at the agencies about competitions and prizes.

\section{Existing technological platform Challenge.gov}

In addition to providing procedural guidance, GSA was also in charge of setting up the shared online platform Challenge.gov. A central approach to solving the technological problems for all participants has encouraged agencies to use the platform knowing that legal barriers regarding the review of the Paperwork Reduction Act were already prescreened and preapproved. One public manager explained that 'we have resources now and connectivity that we could not have envisioned five years ago.' The platform is made available at no-cost to the agencies.

\section{Organizational mimicry}

Agencies that are adopting prizes and challenges slower than others reported that they tend to mimic already existing behaviour from agencies that were able to jump onto the bandwagon earlier:

Outside of [the interviewee's agency], NASA has done some fairly innovative things, and GSA. Other government agencies that I have seen as being innovative, or doing [open] innovation, or using [open] innovation to solve their problems: the office of the National Coordinator is very forward leading in that area.

Mimicry does not only flow from the outside in (mimicking NASA's or GSA's innovative behaviour), but also within a larger department, public managers copy each other's behaviour and learning from each other. 


\section{Extra-organizational and societal drivers}

Extra-organizational or societal drivers include factors that occur outside government as an institution. Public managers are picking up general technological or behavioural trends that allow them to rethink their internal needs or existing mechanisms, which might lack opportunities to initiate innovations, or even to reach out to those parts of their stakeholders they usually cannot reach through the existing channels. With the previous wave of e-government, using social media to reach out to citizens, public managers have already made positive experiences collaborating with citizens and feel comfortable to structure these outreach mechanisms through a central platform. A public manager explained his agency's positive experiences that drove the Challenge. gov approach:

We ran probably the largest and one of the earliest sort of video contests, during the H1N1 flu issue. We ran a contest where we solicited videos from the public to talk about prevention of H1N1. A significant amount take on that and participation of the public.

Another public manager explained the cultural shift he observed and how his organization picked up the general trends:

This is a new construct: the whole idea of ideation and innovation as a practice or a cultural norm is. There may be elements of it within our culture, we don't formally recognize, or don't formally encourage, but we're moving [into OI], since now that there is awareness, there's the move to formally embrace it, encourage it and 'inculturate' it.

The more experience agencies gain with crowdsourcing mechanisms to engage large amounts of problem solvers, the more they recognize the shift among citizens who want to be in contact with the government. One public manager explains:

We saw that there was a demand and a desire for students to engage with the State Department, but we weren't able to meet that demand through the virtual internship program. We thought let's look at other ways that we can have a lot of the college students engaging with the State Department. Looking at Challenge.gov and other sites, we thought hey, using a challenge type thing is a way to have even more students be involved, and aware of the work that we're doing.

Other agencies explained that the broad participation of problem solvers who were never in touch with government showed them the potential of existing slack capacity among external problem solvers as an indicator for broad societal acceptance of free or low-prized contributions beyond citizens' help to solve government problems.

\section{Finding 2: barriers for OI}

Barriers for the adoption of online OI approaches include legal barriers, uncertainty about the process and its outcomes, technological barriers to design crowdsourcing processes, and most importantly cultural factors that prevent or delay the adoption decisions. Agencies were instructed to find money in their existing budgets to conduct prize contests. The monetary requirements include dedicated personnel, such as department-level point of contacts, and prize money to pay for the winning solutions. In order to get to the point where agency representatives interviewed for this research project launched contests, the institutional barriers had to be addressed. Some of the barriers are rooted in the specific context of government organizations; other barriers are inherently connected to the perceptions and tasks of individuals 
involved in the OI process. Working through these barriers delayed the process for years as one interview explains:

We had to figure out an internal mechanism for making [challenges] happen. That's taken over a year. But, I think it's a year well spent. The America Competes Act supposedly authorizes federal agencies to give prizes. But many agencies don't feel confident in it that actually does provide the right coverage for agencies. Our legal staff definitely did not feel that it was appropriate.

\section{Intra-organizational barriers}

Intra-organizational barriers refer to factors that occur inside each organization and can be solved by the organization itself. These factors include legal, cultural, technical, and institutional barriers.

\section{Legal barriers}

Public managers perceived the absence of a legal framework as risky. One manager mentioned that prizes and contests 'gave everything kind of an air of uncertainty' and that the America Competes Act only provides a vague umbrella framework that is still open for interpretation. Agencies coped with the vagueness and absence of existing rules by borrowing rule structures from agencies that had already implemented prizes and contests and had set a precedent. The existing rules were then adapted to the local contexts.

Examples of legal uncertainty focus on management and targeting of external audiences. These processes are closely regulated through the existing 'cookie' policy (tracking of online user behaviour), measurement, and surveys. Especially, when it comes to personally identifiable information collected by a government agency, section 208 privacy provisions of the e-government act require agencies to conduct a privacy impact assessment (2002). These provisions needed to be adapted to allow new technologies and citizen interactions. However, agencies that target specific audiences struggle with the implementation. One public manager explains:

We had to figure out how kids could be involved. Could they submit something? Do they have to get parental permission? At what age? The second part of that was, we had to customize the entry form on Challenge.gov to ask questions about age to be able to support that, because Challenge.gov, assumes that you are of a certain age.

The second aspect of legal considerations includes intellectual property (IP) rights. While IP issues are arranged by contract in the traditional innovation acquisition processes, these issues had to be re-evaluated for the use of voluntary submissions of knowledge by citizens. In the private sector, several models of co-ownership of submitted solutions or shared patents have evolved (see for example: Belderbosa et al. 2014). In the public sector, however, one public manager explained:

There is a debate going on right now about whether or not, and if someone wins a prize and the government pays them however much money for their best technology solution, if that's a direct pathway for that person to be able to work with government. Can that be used for a sole source justification, can we just get the technology to use as a license, or do we actually have to release another contract and compete for the solution that the government actually buys? There's a lot of disagreement about what the government can do with the technology, especially if we don't write in the rules that there's a government right to the intellectual 
property. But often times, if it's bigger market simulation prizes, people won't participate if the government is going to own their IP.

These legal barriers prevent government organizations to proactively seek out more complex solutions, especially if they are not able to actually implement the results of the contest.

\section{Cultural factors}

The organizational culture factors include several different aspects of the OI process:

(a) type of agency and political context, (b) acceptance of external innovations, and

(c) the lack of top-management support and buy-in.

Individual-level factors depend on the type of agency, as an example, science and technology agencies are more likely to abandon the idea to invite external non-professional problem solvers into their innovation process. The R\&Doriented teams are trained (and hired) to develop answers in-house and might feel that it is their core job to know it all. The result is oftentimes that solutions from non-professional problem solvers are not accepted (Katz and Allen 1982). One public manager in a science agency described the general rejection of the new process:

We're an R\&D and technology development organization. People here believe that they are the best engineers in the world, and so if they can't solve it, nobody can.

Another public manager adds that it is difficult for government employees not to be able to fulfil the requirements of their job: This significant cultural change in the way innovations are acquired challenges employee attitudes:

It is a big shift, because in some ways it is admitting and acknowledging maybe that we the government don't have all the answers and that we can benefit from other people's perspective. It is a cultural shift for people to think that way.

One public manager explained how his agency worked to explore the cultural barriers. Instead of changing the mindsets of those people who were against the implementation of prizes and contests, he says:

Actually, we didn't really work around the culture. We basically found the people who were leading the way, and promoted their data the most and encouraged others to follow the same path.

\section{Technological barriers}

Public managers pointed to the fact that an innovative approach comes with initial resistance due to the newness of the technology itself, and new ways of defining and soliciting input for public sector problems: 'So they look easy, but they are not simple.' The standard way to communicate the need for solutions is directly tied to the existing RFP (request for proposals) process, using language that is industry standard or terms only known to professionals. However, problem statements in the OI process need to be written in plain language - not only closed ended enough to make them understandable to amateur problem solvers, but also open ended enough to allow for innovations the agency has not thought about itself. OI provides a new infrastructure and reverses the highly structured contract process: 
The more fuzzier aspect, the fungible aspect of prize challenges that isn't addressed in the [department's' guidance] is what goes into developing a problem statement, and what goes into developing a successful challenge. That's far more challenging.

Previous research on OI processes in the private sector has shown that the degree of openness in defining problems is crucial for the success of a contest. Salge et al. showed that too much openness does not support the process and that a guided approach is oftentimes better (2013). The technology itself was not flexible enough to support these steps:

One of the unexpected things is the Challenge.gov site itself is very rigid, in terms of what you can put in there. I thought we were going to be able to have a system where people actually entered their plans online. Instead, what we ended up with was a system where we have a Microsoft Word document as a template. They complete their template separately, and then they upload that. So that was a surprise to me, for the way the Challenge.gov worked. The technical limitations, word limits, letter limits.

\section{Uncertainty about innovation outcomes}

Public managers confronted with the use of contests and challenges need to adapt to a new organizing process that challenges their current standard operating structure, such as contract management. In the standard acquisition process, expectations, framing, contractual and legal statements are clearly designed and have been codified as organizational knowledge in handbooks and operating manuals.

In addition to the concerns about the design elements of an OI process, public managers are reluctant about innovation outcomes. Public managers, trained to explicitly define the deliverables for a contract or grant, now have to accept that OI is designed to find answers for problems that do not have a predefined solution. In combination with uncertainty about the boundaries and capabilities of the solver community, public managers therefore expressed high degrees of uncertainty about the innovation outcomes:

\footnotetext{
We didn't know how to solve the problem. Not that we could have created an RFP, where we were confident would have been the right way to solve the problem. We knew the problem that needed to be solved was proliferating the use and availability of Blue Button Personal Health Records. What we didn't know was what the best way to go about doing that. We wouldn't have been able to say to industry: Here's what we're looking for: This particular way to proliferate the availability of use.
}

\section{Institutionalization barriers}

After agencies overcame policy, process, and legal barriers, organizational responsibilities needed to be redefined to institutionalize OI in the existing organizational structure. One public manager explains how difficult it was for his agency to start to incorporate contests into the standard operating procedures:

This is because the concept is not to set up an office of innovation, and not have a place that does innovation, and do this with more of an [institutionalization], and making it part of the [department's] culture. There is no office, and there's also no chief innovator, and there's no one who hashes it out. There is no concrete structure that people can go to and say oh good, the Office of Innovation helped me with this.

This ad hoc process shows how agencies are struggling with the institutionalization and the lack of organizational structure in early phases of the adoption process. Previous research has shown that organizational structure will eventually follow strategies (or 
policies in the government context) (Burgelman 1983). The initial lack of organizational structure has led to dedicated organizational roles in other parts of the government system. As an example, the City of Boston and the City of Philadelphia have institutionalized an Office of Innovation and a Chief Innovation Officer role.

Similar to institutionalization of organizational roles, the organizational culture is slowly changing from a closed innovation paradigm to an open paradigm where experimentation is part of a trial and error process. One public manager explains that while there is top management support, lower ranks might not be on board and hinder institutionalization:

The top levels of leadership that would be the assistant secretary and the deputy assistant secretary; there is support, and enthusiasm. The senior leadership below them and then some of the leadership in the different management levels however getting them to embrace this construct and this culture of innovation, which is a little different than some of them may be used to. They, being innovative and doing innovative things implies a certain amount of inherent risk, and they are by definition risk adverse. That is counter intuitive to the way their structure operates.

As a result, public managers avoid experimentation. Government's existing culture does not allow what one interview partner called a safe environment 'to take smart risks' and he called for 'a place to take risks, a place where failing is ok. Don't punish people for failing if you told them you wanted them to take a risk. You can't encourage smart risk taking and then punish failure.'

\section{Inter-organizational barriers}

Hurdles that cross different government organizations occur only when two or more agencies have to actively collaborate and interview partners reported mostly barriers in the initial set-up. Legal barriers expand beyond intra-organizational needs to start to use OI and have to be resolved in a time consuming manner. Collaborative contests with shared promotion and outcomes include for example the First Lady's collaboration with the Department of Agriculture to run the Apps for Healthy Kids challenge, or the Department of Health and Human Services' collaboration with the Environmental Protection Agency and their My Air, My Health challenge. One public manager explained the process:

\footnotetext{
Interagency bureaucratic challenges of doing an Interagency Memorandum of Understanding, an MOU, have proven to be quite challenging. Each agency gets its own funds; it is charged with investing in the program sand projects that will help it achieve its mission. Everyone believes that if we could work better across agencies that we would be better coordinated and we might more quickly overcome some of the challenges that we have in terms of clean energy and wellbeing and so forth. But there are still a lot of bureaucratic hurdles that are just there. I want to simplify the process so that any agency that is interested in doing a Big Data challenge can. I could make the process as simple as possible for them to engage, rather than it being a horrendous process. So every time we want to do a new contest, we have to set up a whole new MOU framework.
}

These inter-organizational barriers highlight the need for directions from the Office of Management \& Budget as agencies gain more experience and recognize opportunities for inter-organizational collaboration. 


\title{
Extra-organizational and societal factors
}

Extra-organizational barriers are far less prevalent than extra-organizational drivers. Barriers in this context mostly focus on mindfulness of how changes in internal processes and government experimentation with innovative policies might be perceived by the public. In traditional procurement processes, accountability is built into the process with exact guidelines, reporting structures, and accountability measures that are designed to keep a close watch of appropriateness of managerial actions:

We as federal employees are good stewards of the taxpayers' money that we're entrusted with using; especially if we're using it in a contract mechanism to procure goods and services from outside the federal government. That being said, it's not a clean line of sight. It's not a straight line between Point A and Point B as far as how we do [OI].

Furthermore, monetary incentives and the publicness of the selection and judging process provide ground for concern:

\begin{abstract}
How we manage money is [regulated in the America Competes Act], specifically how we can use appropriated funds as a cash prize in a contest. It also says we can work with other agencies and departments to do this, and it says we can partner not just within the federal government, but with nonfederal partners to do that. So that makes it more clear cut for us. It helps make the line a little straighter between Point A and Point B. Competes actually made challenges easier to use because it more clearly defined the rules for us as federal employees using you know, taxpayer money.
\end{abstract}

\section{Discussion and conclusions}

This article provides empirical evidence for factors driving and hindering government organizations to adopt and implement a new policy instrument called Prizes and Challenges in the US federal government. To gain a deeper understanding of how the internal strategic and managerial decision-making processes are influenced by these factor and ultimately lead to the outcomes observable on Challenge.gov, this article provides a framework on three dimensions: intra-, inter-, and extra-organizational factors. The data include agencies involved in this form of innovation acquisition and adds to our understanding of how OI online practices diffuse in the public sector.

OI was introduced as a new umbrella concept for inviting external, non-professional problem solvers to help government find solutions for problems they weren't able to solve internally or with the help of the standard innovation instruments grants and contracts. The current OI literature focusses on private sector organizations (for a review, see West and Bogers 2014). Based on one embedded case study - the use of the online platform Challenge.gov - and a policy instrument 'Prizes and Contests' of the US federal government, the barriers and drivers for the implementation and use of the platform are analysed. This article shows the complexity of issues that public sector organizations have to deal with when they are confronted with a political mandate to innovate as opposed to private sector organizations. In addition, OI approaches don't only need a crowdsourcing platform, but public managers need to be empowered to take risks and step outside the risk-free request for proposal process in traditional acquisition routines. 
Barriers occur on the inter- and extra-organizational levels making it increasingly complex for government organizations to adopt a new technology. The summary overview in Table 1 shows the need to study the resulting implementation strategies of those agencies that did not reject the adoption of OI. The drivers provide insights about the changing needs of government organizations for a pathway to access innovative ideas from outside of government. Existing innovation acquisition instruments as part of the innovation paradigm limit government organizations to involve those problem solvers who are not part of the formal acquisition process. Open advertising possibilities and collection of the crowdsourced innovations allow government to use e-governance mechanisms that were not previously available.

This article also adds to the literature on co-production and co-design of public services (Joshi and Moore 2004; Osborne, Radnor, and Strokosch 2016; Boivard 2007). While previous research on co-production has mostly focussed on inclusion of citizens in form of public participation processes to gain their support, trust, and insights in structured decision-making processes, OI opens a new conduit to include external knowledge into the problem-solving processes. OI is however significantly different from previous waves of co-production and leads to innovative ideas and solutions by providing monetary incentives and using online platforms to broaden the inclusion of ideas and not only local participation.

In addition to the existing OI literature, previous research on e-government has mostly focussed on internal barriers or drivers. This article shows that external barriers and drivers are out of the control of a single agency and equally important in adoption and implementation decisions of an e-government innovation.

The findings highlight the opportunity to review what the innovations outcomes are and what their potential impact is on the innovation process itself and the broader innovation culture in government. Most of the current e-government and OI research focusses on the diffusion and adoption decision; however, there is no research that looks at short-term innovation products and long-term changes in the organization. It is important to study the outcomes of the OI process beyond the number of solutions submitted from citizens during the crowdsourcing process, which can only indicate interest in a given topic, but says little about the value of the innovation. Indirect outcomes, such as legitimization of an innovative acquisition process, public value creation, or the changing climate towards external innovations in government, can be studied to understand the extent of the impact on government.

\section{Limitations}

This research is clearly limited by its focus on a specific layer of the US federal government's executive branch situated in a specific political climate: President Obama's administration's push for an agile government with the use of new technologies. As one of the first studies on OI in the public sector, the framework developed here can help researchers design their own OI inquiries or conduct comparative public administration research. The inclusion of a variety of government agencies with diverse sets of missions and mandates contributes to our understanding of how government agencies implement OI given their own political context, differences in top-management sentiments towards innovation, and diverse organizational cultures.

The interview partners selected for this study do not only focus on successful cases. The nature of the study helps to understand what makes OI approaches 
Table 1. Summary of findings: drivers and barriers of open innovation in the public sector.

\begin{tabular}{|c|c|c|}
\hline Level & Drivers & Barriers \\
\hline Intra-organizational & $\begin{array}{l}\text { Pre-policy time frame: } \\
\text { - Internal experimentation } \\
\text { Post-policy time frame: } \\
\text { - Top-down management decision } \\
\text { - Strategic alignment with mission } \\
\text { - Necessity to change existing innova- } \\
\text { tion acquisition framework } \\
\text { - Recognizing unsolvable internal } \\
\text { public management problems } \\
\text { - Opportunity to connect with new } \\
\text { community of problem solvers }\end{array}$ & $\begin{array}{l}\text { Type of agency: } \\
\text { - Adoption speed } \\
\text { - Regulatory barriers (extent to which } \\
\text { agencies are allowed direct citizen } \\
\text { interaction) } \\
\text { Legal aspects: } \\
\text { - Properties of submitted solutions } \\
\text { - Collection of PII through contests } \\
\text { - Time lag from decision to } \\
\text { implementation: } \\
\text { (a) Working through organizational bar- } \\
\text { riers: } 2 \text { years } \\
\text { (b) Simple } \rightarrow \text { complex public manage- } \\
\text { ment problems } \\
\text { Cultural aspects: } \\
\text { - NiH syndrome } \\
\text { - Inertia: waiting out policy waves, lea- } \\
\text { dership changes ('trickle down') } \\
\text { Procedural aspects: } \\
\text { - Understanding crowdsourcing } \\
\text { - Drocesses } \\
\text { - Desining public management problems } \\
\text { - Monetary/Non-monetary contests }\end{array}$ \\
\hline $\begin{array}{l}\text { Inter-organizational } \\
\text { factors }\end{array}$ & $\begin{array}{l}\text { - GSA \& OSTP guidance, best practices, } \\
\text { innovators toolkit, roadshows, } \\
\text { webinars } \\
\text { - Organizational mimicry of existing } \\
\text { practices } \\
\text { - Existing technological platform to } \\
\text { promote challenge and collect ideas }\end{array}$ & - Legal: MOUs \\
\hline $\begin{array}{l}\text { Extra-organizational } \\
\text { factors }\end{array}$ & $\begin{array}{l}\text { - Introduction of new policy instru- } \\
\text { ment through Presidential mandate } \\
\text { National Priorities (e.g. eco- } \\
\text { nomic development) } \\
\text { - Digital Government Strategy } \\
\text { - Societal acceptance of crowdsour- } \\
\text { cing processes }\end{array}$ & $\begin{array}{l}\text { - Recruiting of 'unreachables': weak ties } \\
\text { to otherwise disconnected citizens } \\
\text { - Expectations of professional problem } \\
\text { solvers vs. general citizenry } \\
\text { - Power distance/cultural distance: we vs. } \\
\text { them mentality }\end{array}$ \\
\hline
\end{tabular}

NIH: Not invented here; PII: personally identifiable information.

unsuccessful for some government actors, as opposed to others who given the alignment of OI policy instrument and e-government platform with their organizational mission made it very successful.

In conclusion, OI - even several years after it was officially introduced through a Presidential mandate in the US federal government - is still in its early stages. Each agency has to work through not only legal barriers, but also cultural internal barriers. 
Only in cases where there is clear alignment with the organizational mission and openness of the organizational culture, agencies attempt to adopt (oftentimes low risk) prizes and contests. While some agencies have waited for a Presidential mandate like to allow them to innovate in an open format, clearly for other agencies, the mandate is a burden and they reject a sustainable implementation of OI.

\section{Disclosure statement}

No potential conflict of interest was reported by the author.

\section{Notes on contributor}

Ines Mergel is full professor of public administration at the Department of Politics and Public Administration at the University of Konstanz. Her research focusses on digital transformation, innovative use of new technologies, and networked governance. She currently serves as the Associate Editor of Government Information Quarterly.

\section{ORCID}

Ines Mergel (D) http://orcid.org/0000-0003-0285-4758

\section{References}

Arundel, A., L. Casali, and H. Hollanders. 2015. "How European Public Sector Agencies Innovate: The Use of Bottom-Up, Policy-Dependent and Knowledge-Scanning Innovation Methods." Research Policy 44 (7): 1271-1282. doi:10.1016/j.respol.2015.04.007.

Belderbosa, R., B. Cassimana, D. Faemsa, B. Letena, and B. Van Looy 2014. "Co-Ownership of Intellectual Property: Exploring the Value-Appropriation and Value-Creation Implications of CoPatenting with Different Partners." Research Policy 43 (5): 841-852. doi:10.1016/j. respol.2013.08.013.

Benkler, Y. 2006. The Wealth of Networks: How Social Production Transforms Markets and Freedom. New Haven, CT: Yale University Press.

Boivard, T. 2007. "Beyond Engagement and Participation: User and Community Coproduction of Public Services." Public Administration Review 67 (5): 846-860. doi:10.1111/j.15406210.2007.00773.x.

Burgelman, R. A. 1983. "A Model of the Interaction of Strategic Behavior, Corporate Context, and the Concept of Strategy." Academy of Management Journal 8 (1): 61-70.

Chesbrough, H. 2003. Open Innovation: The New Imperative for Creating and Profiting from Technology. Cambridge, MA: Harvard Business Press.

Chesbrough, H., and A. K. Crowther. 2006. "Beyond High Tech: Early Adopters of Open Innovation in Other Industries." ReD Management 36 (3): 229-236. doi:10.1111/j.1467-9310.2006.00428.x.

Coglianese, C. 2004. "E-Rulemaking: Information Technology and the Regulatory Process." Administrative Law Review 56 (2): 353-402.

Colatat, P. 2015. "An Organizational Perspective to Funding Science: Collaborator Novelty at DARPA.” Research Policy 44 (4): 874-887. doi:10.1016/j.respol.2015.01.005.

Congress, 110th. 2007. "America COMPETES Act." In H.R.2272, edited by 110th Congress. Washington, DC: Library of Congress.

Dahlandera, L., and H. Piezunkab. 2014. "Open to Suggestions: How Organizations Elicit Suggestions through Proactive and Reactive Attention." Research Policy 43 (5): 812-827. doi:10.1016/j.respol.2013.06.006.

de Sousa Santos, B. 1998. "Participatory Budgeting in Porto Alegre: Toward a Redistributive Democracy.” Politics \& Society 26 (4): 461-510. doi:10.1177/0032329298026004003. 
DeHart-Davis, L., J. Chen, and T. D. Little. 2013. "Written versus Unwritten Rules: The Role of Rule Formalization in Green Tape.” International Public Management Journal 16 (3): 331-356. doi:10.1080/10967494.2013.825193.

Denzin, N. K., and Y. S. Lincoln. 2011. "Introduction: The Discipline and Practice of Qualitative Research." In The Sage Handbook of Qualitative Research, edited by N. K. Denzin and Y. S. Lincoln, 1-19. Thousand Oaks, CA: Sage.

Du, J., B. Leten, and W. Vanhaverbeke. 2014. "Managing Open Innovation Projects with ScienceBased and Market-Based Partners." Research Policy 43 (5): 828-840. doi:10.1016/j. respol.2013.12.008.

E-Government Act of 2002, Public Law 107-347-DEC. 17 2002, Issuing Organization: 107th U.S. Congress, Washington, DC.

Ettlie, J. E., and J. M. Elsenbach. 2007. “The Changing Role of R\&D Gatekeepers." ResearchTechnology Management 50 (5): 59-66.

Felina, T., and T. R. Zenger. 2014. "Closed or Open Innovation? Problem Solving and the Governance Choice.” Reearch Policy 43 (5): 914-925. doi:10.1016/j.respol.2013.09.006.

$\mathrm{Fu}, \mathrm{X}$. 2012. "How Does Openness Affect the Importance of Incentives for Innovation?" Research Policy 41 (3): 512-523. doi:10.1016/j.respol.2011.12.011.

Gambardella, A., and C. Panico. 2014. "On the Management of Open Innovation." Research Policy 43 (5): 903-913. doi:10.1016/j.respol.2013.12.002.

Howe, J. P. 2006. “The Rise of Crowdsourcing.” Wired Magazine Online 14 (6). https://www.wired. com/2006/06/crowds/

Jeppesen, L. B., and K. R. Lakhani. 2010. "Marginality and Problem-Solving Effectiveness in Broadcast Search.” Organization Science 21 (5): 1016-1033. doi:10.1287/orsc.1090.0491.

Joshi, A., and M. H. Moore. 2004. "Institutionalised Co-Production: Unorthodox Public Service Delivery in Challenging Environments." Journal of Development Studies 40 (4): 31-49. doi:10.1080/00220380410001673184.

Katz, R., and T. J. Allen. 1982. "Investigating the Not Invented Here (NIH) Syndrome: A Look at the Performance, Tenure, and Communication Patterns of $50 \mathrm{R} \& \mathrm{D}$ Project Groups." R\&D Management 12 (1): 7-20. doi:10.1111/radm.1982.12.issue-1.

Lakhani, K. R., and L. B. Jeppesen. 2007. "Getting Unusual Suspects to Solve R\&D Puzzles.” Harvard Business Review 85: 5.

Lee, S. M., T. Hwang, and D. Choi. 2012. "Open Innovation in the Public Sector of Leading Countries.” Management Decision 50 (1): 147-162. doi:10.1108/00251741211194921.

Meijer, A. 2015. "E-Governance Innovation: Barriers and Strategies." Government Information Quarterly 32 (2): 198-206. doi:10.1016/j.giq.2015.01.001.

Mergel, I. 2015. "Opening government: Designing Open Innovation Processes to Collaborate with External Problem Solvers." Social Science Computer Review 33 (5): 599-612.

Mergel, I., and K. Desouza. 2013. "Implementing Open Innovation in the Public Sector: The Case of Challenge.Gov." Public Administration Review 73 (6): 882-890. doi:10.1111/puar.2013.73. issue-6.

Mergel, I., S. I. Bretschneider, C. Louis, and J. Smith. 2014. "The Challenges of Challenge.Gov: Adopting Private Sector Business Innovations in the Federal Government." In Proceedings of the 2014 47th Hawaii International Conference on System Sciences (HICSS), 2073-2082. Washington, DC: IEEE.

Miles, M. B., A. M. Huberman, and J. Saldana. 2014. Qualitative Data Analysis: A Methods Sourcebook. 3rd ed. Thousand Oaks, CA: Sage.

Murray, F., S. Stern, G. Campbell, and A. MacCormack. 2012. "Grand Innovation Prizes: A Theoretical, Normative, and Empirical Evaluation.” Research Policy 41 (10): 1779-1792. doi:10.1016/j.respol.2012.06.013.

NASA. n.d. “Asteroid Initiative: NASA's Asteroid Redirect Mission and Grand Challenge.” http:// www.nasa.gov/mission_pages/asteroids/initiative/-.U-T1bPldXTo

Osborne, S. P., Z. Radnor, and K. Strokosch. 2016. "Co-Production and the Co-Creation of Value in Public Services: A Suitable Case for Treatment?” Public Management Review 18 (5): 639-653. doi:10.1080/14719037.2015.1111927.

Piezunka, H., and L. Dahlander. 2015. "Distant Search, Narrow Attention: How Crowding Alters Organizations' Filtering of Suggestions in Crowdsourcing." Academy of Management Journal 58 (3): 856-880. 
Rainey, H. G., S. Pandey, and B. Bozeman. 1995. "Research Note: Public and Private Managers' Perceptions of Red Tape.” Public Administration Review 55 (6): 567-574. doi:10.2307/3110348.

Ropera, S., P. Vahterb, and J. H. Lovec. 2013. "Externalities of Openness in Innovation." Research Policy 42: 1544-1554. doi:10.1016/j.respol.2013.05.006.

Salge, T. O., T. Farchi, M. I. Barrett, and S. Dopson. 2013. "When Does Search Openness Really Matter? A Contingency Study of Health-Care Innovation Projects." Journal of Product Innovation Management 30 (4): 659-676. doi:10.1111/jpim.12015.

Shirky, C. 2008. Here Comes Everybody: The Power of Organizing without Organizations. New York: Penguin.

Surowiecki, J. 2004. The Wisdom of Crowds. New York, NY: Knopf Doubleday.

The White House. 2009. The Open Government Initiative. edited by Executive Office of the President. Washington, DC: White House.

The White House. 2010. Guidance on the Use of Challenges and Prizes to Promote Open Government Edited by Office of Management and Budget. Washington, DC: Exectuvie Office of the President.

Villarroel, J. A. 2013. "Strategic Crowdsourcing: The Emergence of Online Distributed Innovation." In Leading Open Innovation, edited by A. S. Huff, K. M. Moeslein, and R. Reichwald, 171-200. Cambridge, MA: The MIT Press.

West, J., and K. R. Lakhani. 2008. "Getting Clear about Communities in Open Innovation." Industry \& Innovation 15: 223-231. doi:10.1080/13662710802033734.

West, J., and M. Bogers. 2014. "Leveraging External Sources of Innovation: A Review of Research on Open Innovation." Journal of Product Innovation Management 31 (4): 814-831. doi:10.1111/ jpim.2014.31.issue-4. 